\title{
XÂY DỤ̂nG MÔ HÌNH GIẢNG DẠY CDIO CHO SINH VIÊN NGÀNH ĐIỆN TỬ NHẰM VẬN DỤNG KIẾN THỨC CHUYÊN MÔN VÀ NHU CẦU THỰC TẾ
}

\author{
Nguyễn Thị Hiền(*), Nguyễn Thị Huệ(*), Võ Hồng Ngân(*) \\ (*) Thạc sĩ. Truoòng Đại học Công nghệ Đồng Nai. Email: nguyenthihien@ dntu.edu.vn
}

DOI: $\underline{10.37550 / \mathrm{tdmu} . \mathrm{CFR} / 2021.01 .102}$

\section{Tóm tắt}

Bài báo này đề cập đến chuơng trình đào tạo sinh viên ngành Công nghệ Kỹ thuật điện tử kéo dài 4 năm đã được triển khai tại trường Đại học Công nghệ Đồng Nai. Các sinh viên phát triển kiến thức và kỹ năng tù người mới hoc điện tử trở thành người có kinh nghiệm nhu các nhà thiết kế mạch. Chuơng trình đào tạo mang tính định hướng cao và tất cả các học phần đều tập hợp xung quanh một bộ tiêu chuẩn đã được xem xét kỹ luõng. Chưong trình đào tạo đặt trọng tâm vào bốn dụ án thiết kế - triển khai (dự án kỹ thuật, dư án kỹ thuật đa ngành, thực tập chuyên ngành và khóa luận tốt nghiệp) và tuân thủ đúng các nguyên tắc CDIO (Conceive - Design - Implement - Operate: Hình thành - Thiết kế Triển khai - Vận hành). Ở năm đầu tiên, dư án có độ khó thấp, thách thức tăng lên đáng kể trong nhũng năm tiếp theo. Sinh viên học được rằng thiết kế sản phẩm là một quá trình lặp đi lặp lại ở các cấp độ khác nhau. Các đánh giá đã chứng minh rằng sinh viên không chỉ nhận thức được các nguyên tắc CDIO mà còn bị thuyết phục bởi chất lượng đào tạo khi tuân theo các tiêu chuẩn này.

Từ khóa: thiết kế - triển khai, trải nghiệm học tập tích hợp, học tích cưcc

\section{1. Đặt vấn đề}

Trong hệ thống giáo dục đại học, người ta có thể chia các chương trình đào tạo ở ba cấp độ. Cấp độ đầu tiên là đào tạo đại học bốn năm và được gọi là cử nhân chuyên nghiệp hoặc kỹ sư. Thứ hai là đào tạo thạc sĩ, cấp độ này yêu cầu sáu năm học, bao gồm bốn năm cử nhân (hoặc kỹ sư) và hai năm học thạc sĩ. Cấp độ thứ ba là đào tạo tiến sĩ, bao gồm bốn năm cử nhân, hai năm thạc sĩ và 3 năm học tiến sĩ. Để thuận tiện cho việc đào tạo có tính kế thừa giữa 3 cấp độ trên, nhà trường đã xây dựng chương trình đào tạo ngành Công nghệ kỹ thuật điện tử nhấn mạnh mối liên hệ giữa các cơ sở lý thuyết và ứng dụng thực tế nhằm tuân thủ các nguyên tắc $\mathrm{CDIO}$ được tốt nhất. Đồng thời, các học phần được sắp xếp theo trình tự sao cho phù hợp nhất với khả năng của người học. Chương trình đào tạo kỹ sư ngành điện tử tập trung vào 6 tiêu chuẩn khác nhau, trong đó ngoài các tiêu chuẩn về kiến thức và kỹ năng cơ bản - là các kỹ năng cốt lõi - còn lồng ghép các kỹ năng khác như kỹ 
năng thuyết trình, kỹ năng giao tiếp, kỹ năng làm việc nhóm... Trong cấu trúc chương trình, có những học phần giảng dạy theo dự án là chính thì giảng viên chia các đề tài theo cấp độ khó khác nhau. Sinh viên có thể tự chọn phạm vi đề tài của mình để đạt được mức điểm mong muốn. Sinh viên và giảng viên thường xuyên tương tác với nhau để đạt được kết quả mong đợi. Ngoài ra, mức độ khó của các môn học được tăng lên và sinh viên rút ra bài học rằng: thiết kế và phát triển sản phẩm là một quá trình lặp đi lặp lại quy trình ở nhiều cấp độ trong đó có sự tích hợp của nhiều kỹ năng cứng và kỹ năng mềm. Bốn năm học có bốn dự án lớn với độ khó tăng dần qua các năm nhằm đáp ứng chuẩn đầu ra chương trình đào tạo.

\section{Cấu trúc chuẩn đầu ra}

\subsection{Chuẩn đầu ra}

Thuật ngữ chuẩn đầu ra là một khái niệm giáo dục liên quan đến sự liên kết, cấu trúc và tính logic của một chương trình đào tạo. Chuẩn đầu ra làm rõ chương trình đào tạo giúp người học đạt được những gì sau khi hoàn thành khóa học. Để xây dựng chương trình đào tạo một cách hoàn thiện đòi hỏi phải tham khảo ý kiến của các bên liên quan như sinh viên, các giảng viên, doanh nghiệp, cựu sinh viên và các cố vấn chuyên ngành. Việc duy trì kết quả học tập dự kiến từ đầu đến cuối khóa học cũng đòi hỏi sự điều chỉnh thường xuyên liên tục về nội dung, nguyên tắc giảng dạy và phương pháp kiểm tra.

Một số chuẩn đầu ra có thể tập trung ở một vài học phần nào đó hoặc được lồng ghép cùng với chuẩn đầu ra khác. Bên cạnh chuẩn đầu ra cổ điển, các chuẩn đầu ra cụ thể hơn như kỹ năng giao tiếp hoặc phát triển bền vững ngày càng được quan tâm. Đặc biệt hơn nữa là xây dựng thêm chuẩn đầu ra về khởi nghiệp, hội nhập quốc tế.

\subsection{Tầm nhìn và hoạt động}

Chuẩn đầu ra cung cấp cái nhìn sâu sắc về chương trình đào tạo, sự gắn kết lẫn nhau của các học phần trong khóa học. Nếu muốn tập trung vào kỹ năng nào đó thì cần xây dựng chuẩn đầu ra tương ứng và lựa chọn học phần phù hợp với chuẩn đầu ra đó. Muốn đạt được các chuẩn đầu ra như mong đợi thì người học cần đạt được những mục tiêu cụ thể từ mỗi học phần mang lại. Chuẩn đầu ra cũng cho sinh viên biết họ đang ở giai đoạn nào của khóa học.

Ban biên soạn chương trình đào tạo gồm trưởng khoa, trưởng bộ môn, giảng viên hỗ trợ và sinh viên, đôi khi bổ sung các thành viên từ phòng đào tạo. Ban này đã xác định 6 mục tiêu giáo dục, như một tuyên bố về tầm nhìn và sứ mệnh giáo dục cho sinh viên kỹ thuật điện tử. Nhằm đào tạo ra các kỹ sư điện tử có khả năng: 1 . Làm chủ được lý thuyết và có kỹ năng thực hành chuyên sâu; 2. Biến những ý tưởng khoa học thành những sản phẩm có ích cho xã hội; 3 . Chuyển giao ý tưởng và sản phẩm bằng việc truyền thông quảng bá; 4 . Tự định hướng theo nhóm và làm việc trực tiếp trong lĩnh vực chuyên môn; 5. Có khả năng nghiên cứu đa ngành; 6 . Trở thành chuyên gia trong lĩnh vực 'điện tử tương tự và kỹ thuật số', 'thông tin và công nghệ truyền thông' và 'xử lý dữ liệu và đa phương tiện'.

Các mục tiêu này đã được chuyển đổi thành 6 chuẩn đầu ra khác nhau: chuẩn đầu ra mang tính khoa học cơ bản, chuẩn đầu ra mang tính bền vững/khởi nghiệp, chuẩn đầu ra về 
giao tiếp, chuẩn đầu ra về kỹ thuật, chuẩn đầu ra về nghiên cứu và cuối cùng là chuẩn đầu ra về điện tử. Chúng được hình dung bằng nhiều màu sắc khác nhau như hình 1 .

Cụ thể, ban biên soạn chương trình muốn hiện thực hóa tầm nhìn và tuyên bố sứ mệnh của mình thông qua: 1 . Sáng tạo tri thức như một nền tảng cơ bản của sáng tạo trong thực tế; 2 . Nâng cao khả năng tiếp cận đa ngành, biến những thách thức thành động lực làm việc; 3 . Sử dụng nhiều phương pháp giảng dạy đa dạng và phong phú để rèn luyện kỹ năng giao tiếp; 4. Giải quyết các vấn đề phức tạp, trong đó mỗi thành viên trong nhóm được thử thách để "dám nghĩ"; 5 . Hướng dẫn tư duy học thuật sắc bén trong các dự án và hướng dẫn tự học; 6 . Lĩnh hội kiến thức lý thuyết thông qua các ứng dụng thực tế.

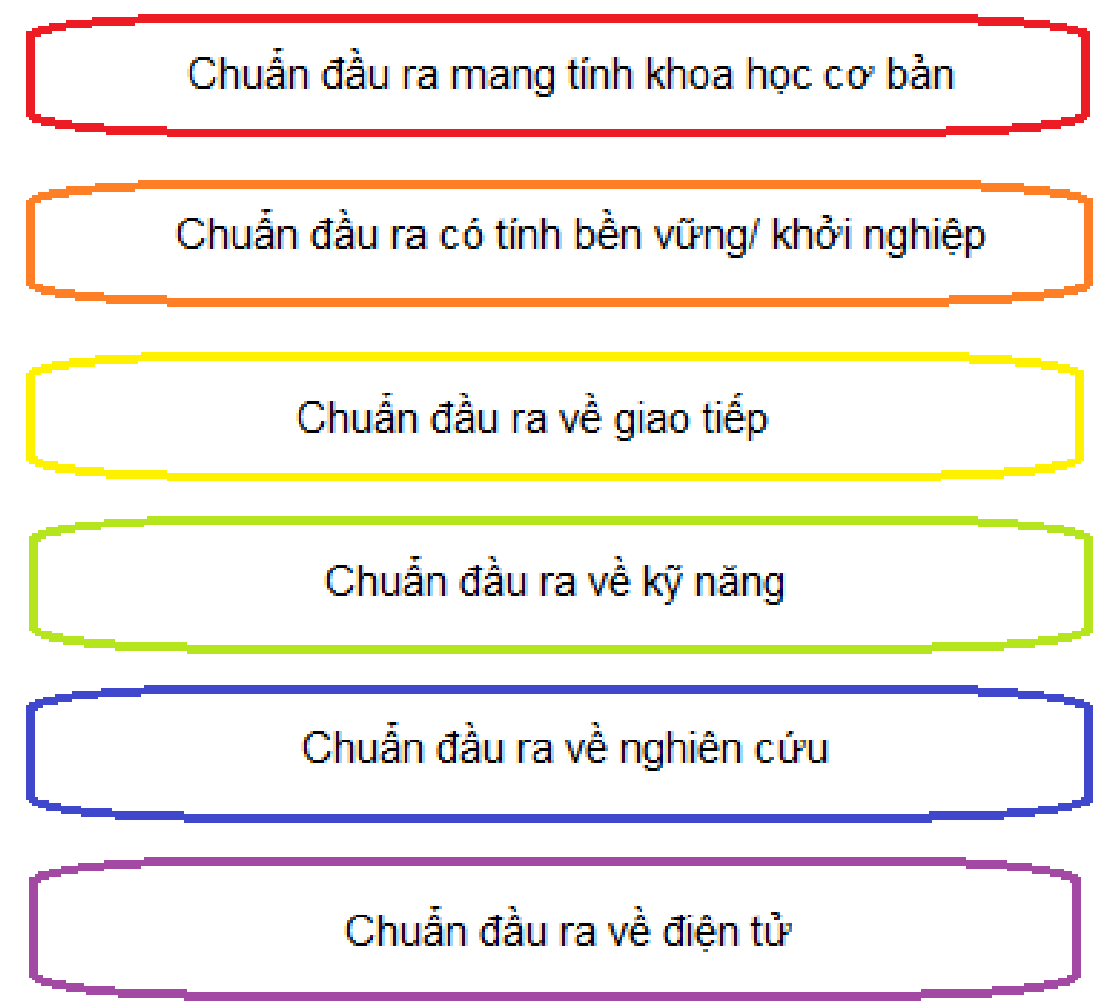

Hình 1. Sáu chuẩn đầu ra khác nhau

Các mục tiêu hoạt động được liên kết trực tiếp với tuyên bố tầm nhìn và sứ mệnh cũng như với chuẩn đầu ra.

\subsection{Ap dụng vào chuơng trình đào tạo}

Việc triển khai các mục tiêu hoạt động dẫn đến sự liên kết ngang và dọc của các học phần. Màu sắc của 6 chuẩn đầu ra khác nhau được sử dụng để hình dung toàn bộ chương trình đào tạo xuyên suốt 8 học kỳ, hoặc 240 tín chỉ (với 30 tín chỉ mỗi học kỳ) như trong hình 2. Đối với mỗi chuẩn đầu ra tương ứng với một hoặc một số học phần, kết nối với nhau nên chương trình đào tạo là một chuỗi cân đối của các đơn vị học phần, hỗ trợ lẫn nhau. Một số học phần của khóa học liên quan đến một hoặc thậm chí với nhiều chuẩn đầu ra và do đó được thiết kế là một hoặc nhiều màu.

Học phần trong hình 2 được đóng khung màu vàng là tập trung nhiều hơn về kỹ năng giao tiếp so với các học phần khác. Tùy theo mỗi học phần mà mức độ đánh giá sẽ khác 
nhau. Ví dụ, trong các học phần có màu đỏ tương ứng với chuẩn đầu ra mang tính khoa học cơ bản (có màu đỏ ở hình 1) thì độ khó trong đánh giá ở mức trung bình.

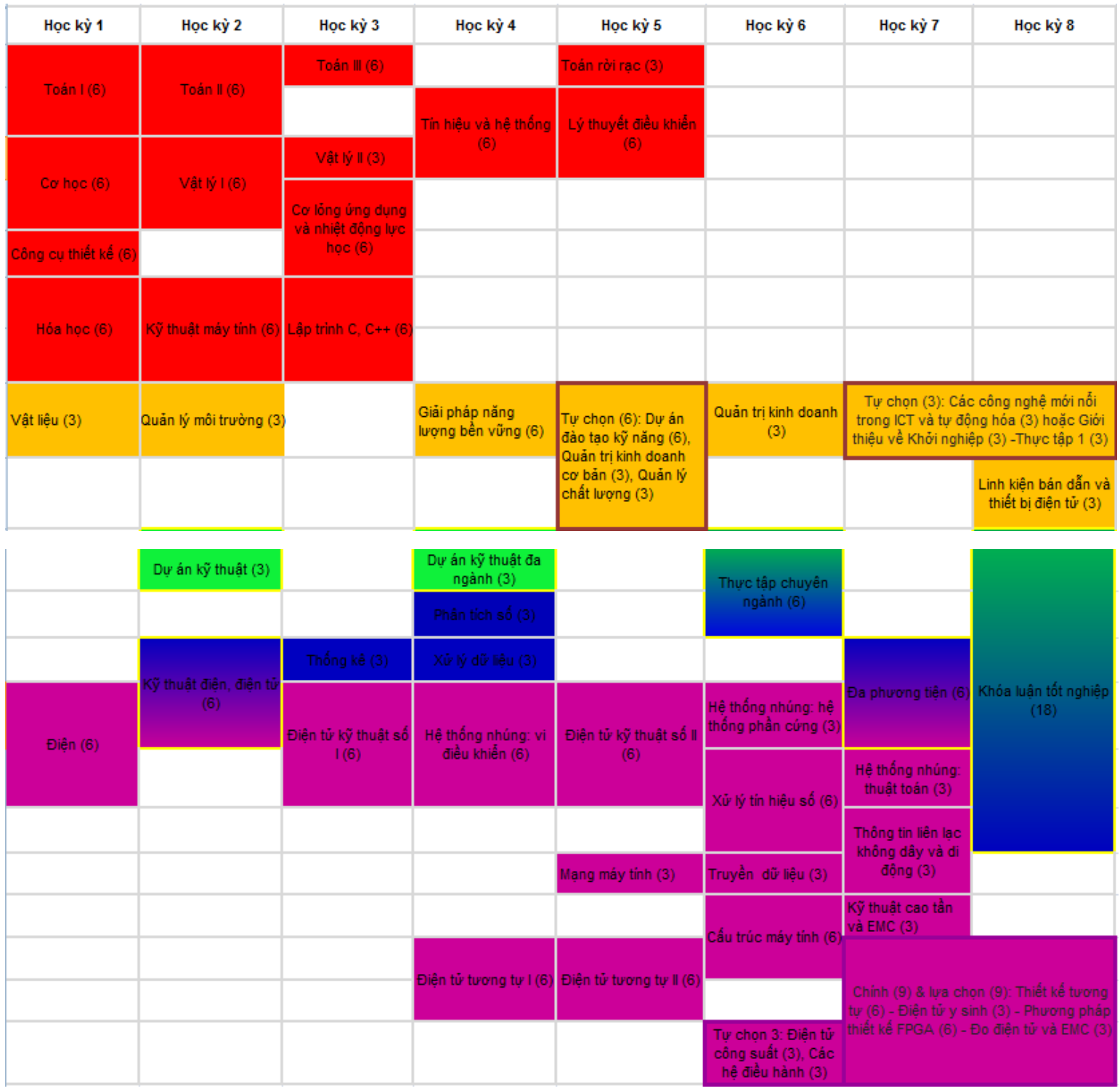

Hình 2. Cấu trúc của chuoong trình đào tạo

\section{Thiết kế - thực hiện dụ̣ án điện tử}

Chuẩn đầu ra về kỹ năng được thực hiện ở các học phần có khung màu vàng (hình 2) nhằm rèn luyện sinh viên học cách suy nghĩ và hành động như một kỹ sư. Theo cấu trúc chương trình thì các dự án thiết kế - triển khai là cốt lõi và được dùng để hỗ trợ, bổ sung cho các học phần lý thuyết khác từ học kỳ trước hoặc trong cùng một học kỳ. Mỗi học phần được tô bởi các màu khác nhau ăn khớp với mỗi màu viền của chuẩn đầu ra ở hình 1 . Nếu một học phần được quy định bởi nhiều màu thì đáp ứng cho nhiều chuẩn đầu ra. Chẳng hạn: học phần Dự án kỹ thuật được tô màu xanh lá thì đáp ứng chuẩn đầu ra về kỹ năng, 
đồng thời nó có viền màu vàng thì cũng gắn kết với chuẩn đầu ra về giao tiếp. Dự án kỹ thuật là học phần đầu tiên về dự án, tiếp theo là Dự án kỹ thuật đa ngành đòi hỏi kỹ năng cao hơn trong năm hai, thực tập chuyên ngành ở năm thứ ba cần kỹ năng cao hơn nữa và kết thúc chương trình là khóa luận tốt nghiệp.

Các học phần có khung màu vàng thì ngoài việc đáp ứng chuẩn đầu ra tương ứng (theo màu được tô) còn đáp ứng chuẩn đầu ra về giao tiếp (tiêu chuẩn CDIO 7). Sinh viên được đào tạo về kỹ năng giao tiếp thông qua nhiều hình thức như việc trình bày trên giấy hoặc áp phích về một nội dung nào đó hoặc truyền đạt chi tiết về cách thiết kế các lựa chọn và kết quả sơ bộ của dự án cho các nhóm khác...Thường xuyên có sự giao tiếp giữa giảng viên với sinh viên và giao tiếp giữa sinh viên với sinh viên để mọi người học hỏi lẫn nhau, hỗ trợ cho nhau hoàn thành môn học được tốt nhất.

Mở đầu của học phần về dự án luôn là buổi giới thiệu để cung cấp các chi tiết kỹ thuật của dự án, phương pháp luận và cách đánh giá dự án. Giảng viên hướng dẫn sử dụng các phương pháp đánh giá khác nhau sao cho phù hợp và khách quan nhất (tiêu chuẩn CDIO 11). Riêng kỹ năng viết và trình bày được đánh giá bởi giảng viên về ngôn ngữ. Sinh viên được giới thiệu về nguyên tắc CDIO một cách kỹ lưỡng để có những định hướng về dự án mình đảm nhận. Các đề tài của dự án là đa ngành (tiêu cuẩn CDIO 8) và tùy thuộc vào mỗi đề tài mà có hay không có bài thuyết trình bổ sung nhằm cung cấp cho sinh viên nền tảng kiến thức liên quan và các vấn đề kỹ thuật cần thiết cho dự án. Nơi làm việc của sinh viên được bố trí thuận tiện và thân thiện (tiêu chuẩn $\mathrm{CDIO}$ 6). Sinh viên phải làm việc cho dự án trong những giờ cụ thể, nhưng có thể dành thêm giờ bất cứ lúc nào.

Giảng viên vừa đóng vai trò là huấn luyện viên vừa đóng vai trò là giám sát viên (tiêu chuẩn CDIO 5), giúp sinh viên nhanh chóng đạt được trình độ tối thiểu theo quy định và thúc đẩy họ đạt được các mục tiêu khác cao hơn.

Bốn học phần đậm tính CDIO mang tính quyết định tay nghề của sinh viên và chuẩn đầu ra về giao tiếp. Lưu đồ với thiết kế - triển khai liên tiếp các dự án được thể hiện trong hình 3.

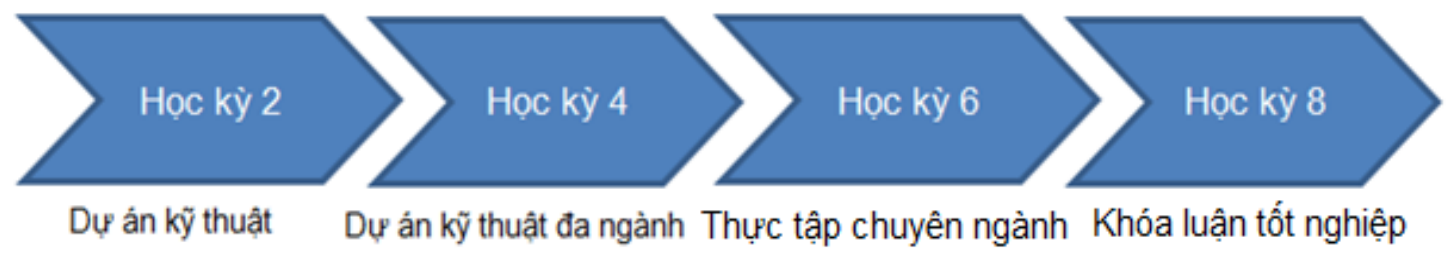

Hinh 3. Các dụ án thiết kế - triển khai liên tiếp

\subsection{Dụ án kỹ thuật}

Trong năm học đầu tiên của ngành điện tử, sinh viên được triển khai dự án kỹ thuật để bước đầu làm quen và triển khai một dự án đầu tay. Sinh viên được chia nhóm gồm 5 đến 7 người thực hiện một động cơ điện, bằng cách sử dụng các thành phần cơ bản về cơ và điện như nam châm và công tắc, yêu cầu kiểm soát động cơ với bảng vi điều khiển Arduino. Tiến độ dự án theo tuần, sinh viên thảo luận trong nhóm cùng với các giám sát viên và chủ động giải quyết vấn đề một cách sáng tạo. 
Về kỹ năng giao tiếp, giảng viên xem xét việc sử dụng đúng và đủ ngôn ngữ trong bài báo cáo và danh sách tài liệu tham khảo. Giảng viên đánh giá về kỹ năng giao tiếp thông qua các cuộc họp dự án và ở buổi bảo vệ dự án. Ở đó, sinh viên làm chủ tọa và thư ký là khác nhau để họ trải nghiệm ở mọi vai trò và phát huy tính linh hoạt, sự chủ động của bản thân.

\subsection{Dụ án kỹ thuật đa ngành}

Trong năm học thứ hai, sinh viên được thử thách với dự án có độ khó hơn là dự án kỹ thuật đa ngành. Dự án này có các nội dung thay đổi theo năm và duy trì độ khó của nó. Năm 2018, các sinh viên đã thiết kế và thi công một bộ thu âm thanh kỹ thuật số dùng trong phát thanh truyền hình. Năm 2019, nhóm sinh viên khác đã thiết kế và thi công máy in 3D 3 màu...Thay vì đổi vai, mỗi sinh viên trong nhóm 5 đến 7 sinh viên cần đáp ứng các hồ sơ công việc khác nhau, nhưng chuyên dụng (ví dụ: quản lý dự án, kỹ sư thiết kế tương tự, kỹ sư thiết kế kỹ thuật số, nhà thiết kế bảng mạch in). Sinh viên tăng cường các cuộc họp nhóm với người giám sát và làm việc tại phòng thí nghiệm nhiều hơn đặc biệt là vào cuối học kỳ.

Ở dự án này, ngoài việc viết bài báo cáo tốt và trình diễn sản phẩm, sinh viên cần tập trung vào kỹ năng thuyết trình trước đám đông. Nên trong cùng học kỳ, một lớp học được tổ chức để dạy cách trình bày một bài báo cáo, các quy định về cấu trúc và bố cục của các slide. Mọi thành viên trong nhóm phải tự chuẩn bị bài thuyết trình và thực hiện thuyết trình luân phiên nhau. Hoạt động này nhằm rèn luyện cho sinh viên cách thể hiện ngôn ngữ cơ thể, cách phát âm và giữ sự chú ý của khán giả. Tổ chức đánh giá kỹ năng thuyết trình trước đám đông cho sinh viên với người đánh giá là các sinh viên ở các nhóm khác.

\subsection{Thụ̂c tập chuyên ngành}

Năm ba của chương trình đào tạo kỹ sư điện tử được kết thúc bằng học phần thực tập chuyên ngành. Dự án này được thiết kế - thực hiện thể hiện vai trò, trách nhiệm lớn hơn của sinh viên. Sinh viên được tham dự phỏng vấn để có cơ hội vào một đơn vị thực tập. Ở đó, mỗi sinh viên được tiếp xúc với môi trường thực tế tại doanh nghiệp và trải nghiệm dưới sự quản lý của nhân viên trong công ty. Người học phải tự thích nghi với môi trường mới, tự tìm tòi học hỏi và tự rèn luyện các kỹ năng nhiều hơn. Ở dự án này, sinh viên có dịp thể hiện cả kỹ năng cứng và kỹ năng mềm đã được tích lũy và rèn luyện trước đây. Trong cấu trúc chương trình đào tạo (hình 2 ), học phần này có màu xanh lục, màu xanh lam và viền màu vàng nên vừa liên quan đến chuẩn đầu ra về giao tiếp, vừa liên quan đến chuẩn đầu ra về nghiên cứu và chuẩn đầu ra về kỹ năng.

Viết báo cáo dự án và thuyết trình thì sinh viên đã có kinh nghiệm trước đây, nhưng trong dự án này, kỳ vọng được đặt ra cao hơn. Đòi hỏi phong cách viết chuyên nghiệp hơn, cấu trúc văn bản chặt chẽ hơn, ngôn ngữ chính xác hơn. Các báo cáo cũng cần phải đầy đủ nhất có thể, vì kết quả sẽ được lưu trữ làm tài liệu tham khảo cho các sinh viên khóa sau.

\subsection{Khóa luận tốt nghiệp}

Khóa luận tốt nghiệp là học phần dự án cuối cùng để sinh viên hoàn thành chương trình đào tạo kỹ sư điện tử. Sinh viên thực hiện nghiên cứu riêng lẻ và độc lập về đề tài đã chọn. Giảng viên hướng dẫn là người đồng hành với mỗi sinh viên trong suốt quá trình làm khóa luận tốt nghiệp. Để đảm bảo đạt được kết quả mong đợi, sinh viên phải thực hiện các nội dung đề tài theo kế hoạch đặt ra và có báo cáo tiến độ với giảng viên phụ trách. Kết thúc thời gian làm khóa 
luận, sinh viên nộp bản báo cáo cho hội đồng bảo vệ khóa luận và chờ sự chấp thuận cho bảo vệ từ các giảng viên phản biện. Hội đồng bảo vệ khóa luận tốt nghiệp được thành lập theo kế hoạch đề ra và mỗi sinh viên tự trình bày báo cáo và trả lời các câu hỏi trước hội đồng. Điểm học phần khóa luận là điểm trung bình chung từ các điểm đánh giá của các thành viên trong hội đồng, điểm đạt theo quy định tín chỉ là từ 4 điểm trở lên.

\section{Bộ tiêu chuẩn CDIO}

Chương trình kỹ thuật điện tử được mô tả ở trên đi kèm với các chuẩn đầu ra đã đề cập. Để đạt được các chuẩn đầu ra đó, trong quá trình thực hiện cũng cần tuân thủ bộ tiêu chuẩn CDIO ứng với thang điểm như sau:

1. Áp dụng nguyên lý chu trình phát triển và triển khai vòng đời của sản phẩm, quá trình và hệ thống hình thành ý tưởng, thiết kế, thực hiện và vận hành - là bối cảnh của giáo dục kỹ thuật (điểm 4/5).

2. Chuẩn đầu ra chi tiết, cụ thể đối với những kỹ năng cá nhân và giao tiếp, những kỹ năng kiến tạo sản phẩm, quy trình, hệ thống, cũng như các kiến thức chuyên môn, phải phù hợp với các mục tiêu của chương trình, xét đến yêu cầu công việc trong tương lai và được chấp thuận của các bên liên quan (điểm 5/5).

3. Chương trình được thiết kế với các học phần chuyên ngành hỗ trợ lẫn nhau, với một kế hoạch rõ ràng để tích hợp các kỹ năng cá nhân và giao tiếp, kỹ năng kiến tạo sản phẩm, quy trình và hệ thống (điểm 4/5).

4. Một môn học giới thiệu mang lại khung chương trình cho thực hành kỹ thuật của việc kiến tạo sản phẩm, xây dựng quy trình và hệ thống, giới thiệu các kỹ năng cá nhân và giao tiếp cơ bản (điểm 4/5)

5. Một chương trình đào tạo bao gồm hai hoặc nhiều môn học hay đồ án trải nghiệm thiết kế - triển khai trở lên, bao gồm một ở cấp độ cơ bản và một ở cấp độ nâng cao (điểm 5/5).

6. Không gian học tập truyền thống và phòng thí nghiệm hỗ trợ và khuyến khích học thực hành trong việc kiến tạo sản phẩm, quy trình và xây dựng hệ thống, kiến thức ngành và kiến thức xã hội (điểm 4/5).

7. Trải nghiệm học tập tích hợp đưa đến sự tiếp thu các kiến thức chuyên ngành, cũng như các kỹ năng cá nhân và giao tiếp, và các kỹ năng kiến tạo sản phẩm, quy trình, và hệ thống. (điểm 5/5).

8. Giảng dạy và học tập dựa trên các phương pháp học tập trải nghiệm chủ động. (điểm 4/5).

9. Các hoạt động nâng cao năng lực của giảng viên về các kỹ năng cá nhân và giao tiếp; các kỹ năng kiến tạo sản phẩm, quy trình và hệ thống. (điểm 3/5).

10. Các hoạt động nâng cao năng lực của giảng viên trong việc cung cấp trải nghiệm học tập tích hợp, trong việc áp dụng các phương pháp học tập trải nghiệm chủ động và trong việc đánh giá việc học tập của sinh viên (điểm 3/5).

11. Đánh giá học tập của sinh viên về các kỹ năng cá nhân và giao tiếp, các kỹ năng kiến tạo sản phẩm, quy trình, hệ thống cũng như kiến thức chuyên ngành (điểm 5/5). 
12. Một hệ thống đánh giá, kiểm định chương trình theo 12 tiêu chuẩn này, bao gồm phản hồi của sinh viên, giảng viên và các bên liên quan khác nhau nhằm mục đích cải tiến liên tục (điểm 5/5).

Trong quá trình triển khai bộ tiêu chuẩn $\mathrm{CDIO}$ nêu trên, nhà trường luôn lưu trữ những hình ảnh, bản kết quả thực hiện để làm minh chứng phục vụ các hoạt động sau này.

\section{Kết luận}

Chương trình đào tạo kỹ sư ngành Công nghệ kỹ thuật điện tử đã được triển khai và bước đầu đã gặt hái được những thành công nhất định. Các môn học được sắp xếp theo trình tự ngang, dọc một cách logic và được quy định một hay một số chuẩn đầu ra tương ứng. Sinh viên được trang bị và rèn luyện kỹ năng nhiều nhất là ở bốn học phần mang đậm tính dự án tương ứng với bốn năm học. Họ được lựa chọn đề tài và vai trò của mình, đồng thời tự do phát triển điểm mạnh của bản thân. Sinh viên cũng được thử sức ở các vị trí khác nhau để trải nghiệm và khắc phục các điểm yếu của mình, đồng thời có trách nhiệm hơn với con đường thu nhận kiến thức đã chọn.

\section{Tài liệu tham khảo}

[1] Khan R., Kristian N., Ying S.Y., \& Jung T.C. (2015). Engineering and Design: an Integrated Course with Real World Projects. Proceedings of the 11th International CDIO Conference, Chengdu, China, June 8-11-2015.

[2] Crawley, E. F., The CDIO Approach To Engineering Education: Introduction, 2010.

[3] https://studiegids.ugent.be/current/EN/studiefiches/E701052.pdf.

[4] http://smo.hcmute.edu.vn/. 